\title{
Analytical and Spectral Study of Furan Ring Containing Organic Ligands
}

\author{
Harshadkumar P. Patel \\ Faculty of Chemistry, S. S. Polytechnic College, Visnagar, India
}

Email address:

hpp.sspc@gmail.com

\section{To cite this article:}

Harshadkumar P. Patel. Analytical and Spectral Study of Furan Ring Containing Organic Ligands. Chemical and Biomolecular Engineering. Vol. 5, No. 1, 2020, pp. 21-25. doi: 10.11648/j.cbe.20200501.14

Received: December 12, 2019; Accepted: December 26, 2019; Published: January 30, 2020

\begin{abstract}
The reaction of Ethyl 5-(piperidin-1-yl-methyl)furan-2-carboxylate with 4-amino salicylic acid afford a 4(5-((diphenylamino)methyl)furan-2-carboxamido)-2-hydroxybenzoic acid (PFSA). The transition metal complexes of $\mathrm{Cu}^{2+}, \mathrm{Co}^{2+}, \mathrm{Ni}^{2+}, \mathrm{Mn}^{2+}$ and $\mathrm{Zn}^{2+}$ of PFSA have been prepared. The objective of the research work is synthesis, characterization and chelating properties of furan ring containing organic ligands. To monitor its antimicrobial activity. PFSA and all the metal complexes were characterized by elemental analyses, spectral studies, magnetic moment determination, molar conductivity measurement. The free ligand and it's complexes have been tested for their antibacterial activities against two types of human pathogenic bacteria the first group is gram positive while the second group is gram negative (by using agar well diffusion method). Finally, it was found that compounds show different activity of inhibition on growth of the bacteria. The conclusion is $\mathrm{Ni}$ (II) $\mathrm{Cu}$ (II), Co (II) and $\mathrm{Mn}$ (II) complexes possess octahedral geometry around the central metal ion.
\end{abstract}

Keywords: Ethyl 5-(Piperidin-1-yl-methyl) Furan-2-Carboxylate, 4-Amino Salicylic Acid, Metal Chelates, Complexes, Spectral Studies, Magnetic Moment, Antibacterial and Antifungal Activity

\section{Introduction}

Literature survey point out that compounds having furan nucleus possesses some diverse biological activities and chemical applications [1] like antimicrobial [2], anthelmintic [3], anti-inflammatory [4], diuretic [5], analgesic [6]. The salicylic acid and its derivatives like 4amino salicylic acid also act as good chelating agents $[7,8]$, as well as potential pharmaceutical products $[9,10]$. The reaction between furan derivative with 4-amino salicylic acid (ASA) has not been reported so far. 4-amino salicylic acid is an excellent anti T. B agent and also acts as a chelating ligand with better microbicidal activity. Hence it was thought interesting to prepare the intermolecular ligands containing furan and salicylic acid moieties. Thus, the present communication comprises the studies on furansalicylic acid combined molecule and its metal chelates. The obtained metal complexes were characterized by different analytical and spectral methods. The research work is illustrated in figure 1.

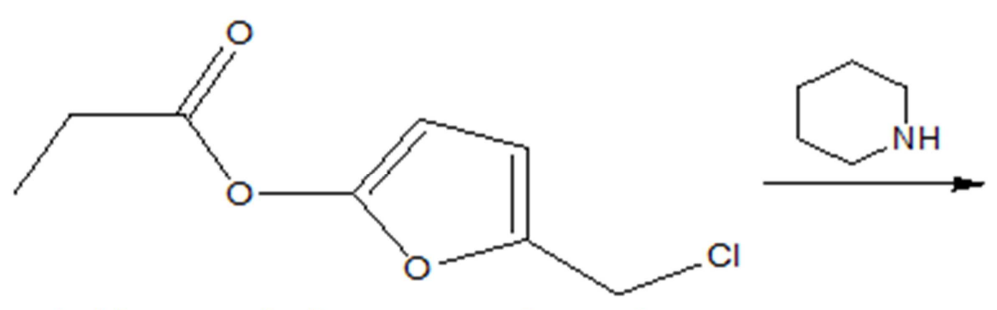




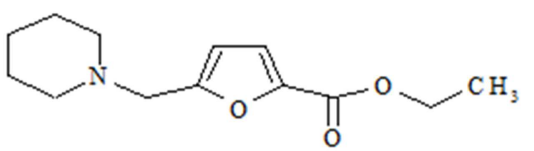

E thyl 5 -(piperidin-1-ylm ethyl)furan-2-carbox ylate

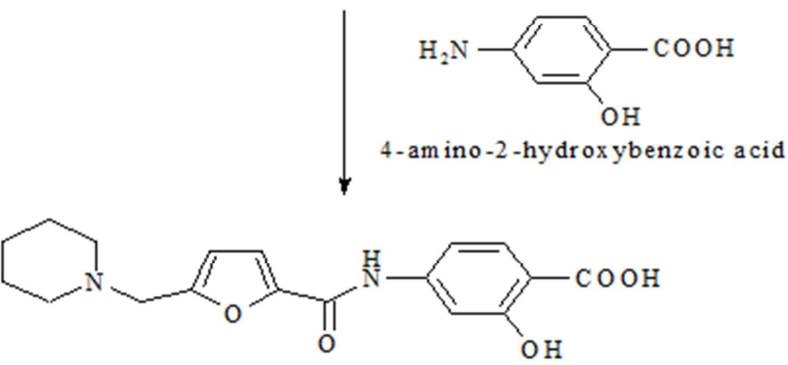

2-hydrox y-4-(5-(piperidin-1-ylm ethyl)furan-2-carbox am ido)benz oic acid

PF SA

$\downarrow$ Metal salt

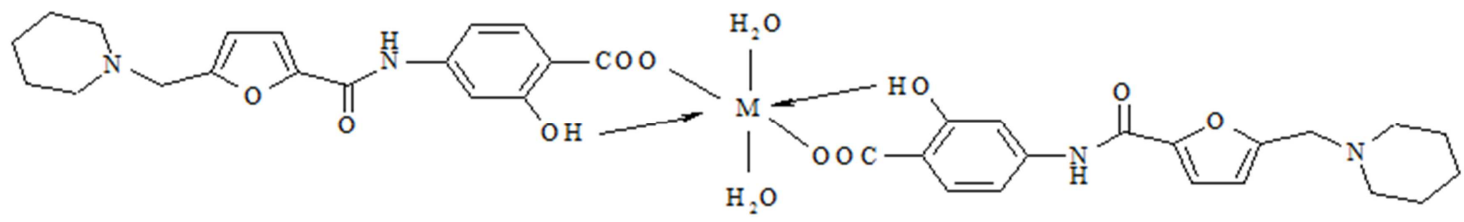

M etal chelate of PFSA

Where, $\mathrm{M}=\mathrm{Cu}^{+2}, \mathrm{Ni}^{+2}, \mathrm{Co}^{+2}, \mathrm{Mn}^{+2}$ and $\mathrm{Zn}^{+2}$

Figure 1. Scheme of Complex of PFSA.

\section{Materials and Methods}

\subsection{Instrumentation}

The elemental analysis for $\mathrm{C}, \mathrm{H}$ and $\mathrm{N}$ were carried out on elemental analyzer TF-EA.1101 (Italy). IR spectra of PFSA and its metal complexes were scanned on a Nicolet 760 FTIR spectrophotometer in KBr. The NMR spectrum of PFSA was scanned on Brucker NMR spectrophotometer using DMSO solvent. The metal content of the metal chelates was performed by decomposing a weighed amount of each metal complexes followed by EDTA titration as reported in literature (Hong et al., 2008). Magnetic susceptibility measurement of all metal complexes were carried out at room temperature by the Gouy mehod. Mercury tetrathiocynatocobalate (II) $\mathrm{Hg}$ [Co (NCS) $\left.{ }_{4}\right]$ was used as a calibrant. The diffused reflectance spectra of solid metal complexes was recorded on a Backman DK Spectrophotometer with a sodid reflectance attachment, $\mathrm{MgO}$ was employed as the reflectance compound. The electrical conductivity of all the complexes was measure in acetonitrile at $10^{-3} \mathrm{M}$ concentration.

\subsection{Materials}

Ethyl furan-2-carboxylate and p-Amino salicylic acid were obtained from local dealer. All other used chemicals were of analytical grade. Ethyl 5-(piperidin-1-yl-methyl)furan-2carboxylate prepared according to literature [11].

\subsection{Synthesis of Ethyl \\ 5-(Piperidin-1-yl-methyl) Furan-2-Carboxylate}

In a $250 \mathrm{ml} \mathrm{RBF}$, Ethyl 5-(piperidin-1-yl-methyl)furan-2carboxylate $(0.01 \mathrm{~mole})$ and $\mathrm{K}_{2} \mathrm{CO}_{3}(0.02 \mathrm{~mole})$ were stirred at room temperature in DMF $(20 \mathrm{ml})$ for $1.5 \mathrm{hrs}$ and pinch of $\mathrm{KI}$ was added. After that piperidine $(0.015 \mathrm{~mole})$ was added to reaction mixture which was refluxed for $6 \mathrm{hrs}$. The reaction mixture was poured into water $(20 \mathrm{ml})$ and the mixture was extracted with diethyl ether. The organic extracts were washed with water, dried over anhydrous sodium sulphate and concentrated to obtain crude product. The residue was recrystallized ethyl acetate from to give pure compound. Yield: $61 \%$, m. p. $112-115^{\circ} \mathrm{C}, \mathrm{IR}, \mathrm{cm}^{-1}$ (KBr): 3325 (amine), 3072 (Ar. C-H), 2925 (aliphatic C-H), 1342 (-CN), 1716 (CO). ${ }^{1} \mathrm{H}$ NMR: $\delta$ 6.52-6.35 $(2 \mathrm{H}, \mathrm{d}$, furan $\mathrm{CH}), 3.82(2 \mathrm{H}, \mathrm{s}$, $\mathrm{CH}_{2}$ ), 2.91-2.31 (6H, q, $\left.\mathrm{CH}_{2}\right), 1.13-1.03\left(9 \mathrm{H}, \mathrm{s}, \mathrm{CH}_{3}\right)$. Anal. Calcd for $\mathrm{C}_{13} \mathrm{H}_{19} \mathrm{NO}_{3}$ (273.29): C, 65.80; H, 8.07; N, 5.90; Found: 64.5; H, 8.10; N, 6.0.

\subsection{Preparation of 2-Hydroxy-4-(5-(Piperidin-1-yl-methyl)) Furan-2-Carboxamido) Benzoic acid [PFSA]}

Ethyl 5-(piperidine-1-ylmethyl)Furan-2-carboxylate (0.01 
mole) and 4-amino salicylic acid (0.01 mole) in 1, 4-dioxane $(50 \mathrm{ml})$ were charged into round bottom flask. To this mixture sodium methanolate $(0.05$ mole $)$ was added and mixture was refluxed on oil bath for 8 hours. Finally the mixture was neutralized by acid or base. The product in form of Buffy precipitate was collected, washed and air dried. Yield of the ligand compound PFSA is $64 \%$ and having melting point- $133-135^{\circ} \mathrm{C}$ (Uncorrected).

Table 1. ELEMENTAL ANALYSIS: $\mathrm{C}_{25} \mathrm{H}_{20} \mathrm{~N}_{2} \mathrm{O}_{5}$ (428.44).

\begin{tabular}{llll}
\hline & $\mathbf{C} \%$ & $\mathbf{H \%}$ & $\mathbf{N \%}$ \\
\hline Calculated & 62.73 & 5.81 & 8.13 \\
Found & 62.70 & 5.80 & 8.10 \\
\hline
\end{tabular}

Acid value of ligand.

$\mathrm{mg}$ of TBAH $/ 1 \mathrm{gm}$ of ligand $=655$.

Number of $\mathrm{COOH}$ group $=1.01$.

Thermogravimetric analysis data of Ligands.

Wt loss at $1^{\text {st }}$ stage of degradation. $=12.80 \mathrm{mg}$.

Calculated value of decarboxylation $=12.78 \mathrm{mg}$.

Table 2. IR Features.

\begin{tabular}{ll}
\hline Wave length $\left(\mathbf{c m}^{-1}\right)$ & Group \\
\hline $3033,1540,1660 \mathrm{~cm}^{-1}$ & Aromatic \\
$1676 \mathrm{~cm}^{-1}$ & $\mathrm{CO}$ \\
$2900-3350 \mathrm{~cm}^{-1}$ & $\mathrm{OH}$ \\
$3425 \mathrm{~cm}^{-1}$ & Sec. NH \\
$3425 \mathrm{~cm}^{-1}$ & Sec. NH \\
$2853,2925 \mathrm{~cm}^{-1}$ & $\mathrm{CH}_{2}, \mathrm{CH}_{3}$ \\
\hline
\end{tabular}

Table 3. NMR (DMSO).

\begin{tabular}{llll}
\hline $\boldsymbol{\delta} \mathbf{p p m}$ & Protons & Nature & Assignment \\
\hline 7.62 to 7.94 & $5 \mathrm{H}$ & Multiplet & Aromatic \\
12.94 & $1 \mathrm{H}$ & Singlet & $-\mathrm{COOH}$ \\
5.12 & $1 \mathrm{H}$ & Singlet & $-\mathrm{OH}$ \\
8.51 & $1 \mathrm{H}$ & Singlet & $-\mathrm{CONH}-$ \\
4.37 & $2 \mathrm{H}$ & Singlet & $-\mathrm{N}-\mathrm{CH}_{2}$ \\
2.52 & $10 \mathrm{H}$ & Multiplet & Piperidine \\
\hline
\end{tabular}

\subsection{Synthesis of Metal Chelates of PFSA}

The $\mathrm{Cu}^{2+}, \mathrm{Co}^{2+}, \mathrm{Ni}^{2+}, \mathrm{Mn}^{2+}$ and $\mathrm{Zn}^{2+}$ metal chelates of DMFSA have been prepared in a similar manner. The general procedure is as follow.

To a solution of PFSA (33.2g, 0.1 mole) in ethanol-acetone $(1: 1 \mathrm{v} / \mathrm{v})$ mixture $(150 \mathrm{ml}), 0.1 \mathrm{~N} \mathrm{KOH}$ solution was added dropwise with stirring. The pasty precipitates were obtained at neutral $\mathrm{pH}$. These were dissolved by addition of water up to clear solution. It was diluted to $250 \mathrm{ml}$. by water and was known as stock solution. $25 \mathrm{ml}$ of the stock solution (which contains 0.01 mole PFSA) was added drop wise to the solution of metal salt ( 0.005 mole for divalent metal ions) in water at room temperature. Sodium acetate or ammonia was added up to complete precipitation. The precipitates were digested by water bath at $80^{\circ} \mathrm{C}$ for $2 \mathrm{~h}$. The digested precipitates of chelates were filtered washed with water and air dried. It was amorphous powder. Yield was almost quantitative. The details are given in Table 4 and Table 5.

Table 4. Analytical Data of the Metal Chelates of PFSA.

\begin{tabular}{|c|c|c|c|c|c|c|c|c|c|}
\hline \multirow{3}{*}{ Empirical Formula } & \multirow{3}{*}{ Yield (\%) } & \multicolumn{8}{|c|}{ Elemental Analysis } \\
\hline & & \multicolumn{2}{|l|}{$\mathrm{C} \%$} & \multicolumn{2}{|l|}{ H\% } & \multicolumn{2}{|l|}{$\mathbf{N \%}$} & \multicolumn{2}{|l|}{ M\% } \\
\hline & & Cal. & Found & Cal. & Found & Cal. & Found & Cal. & Found \\
\hline PFSA & 64 & 62.73 & 62.70 & 5.81 & 5.80 & 8.13 & 8.10 & -- & -- \\
\hline PFSA Cu ${ }^{2+} 2 \mathrm{H}_{2} \mathrm{O}$ & 70 & 55.92 & 56.00 & 5.88 & 6.00 & 6.87 & 7.00 & 7.78 & 7.80 \\
\hline PFSACo ${ }^{2+} 2 \mathrm{H}_{2} \mathrm{O}$ & 62 & 56.43 & 56.40 & 5.94 & 6.00 & 6.93 & 7.00 & 7.30 & 7.30 \\
\hline PFSA Mn ${ }^{2+} 2 \mathrm{H}_{2} \mathrm{O}$ & 63 & 56.52 & 56.50 & 5.95 & 6.00 & 6.94 & 7.00 & 6.81 & 6.80 \\
\hline PFSA Ni ${ }^{2+} 2 \mathrm{H}_{2} \mathrm{O}$ & 69 & 56.24 & 56.20 & 5.92 & 6.00 & 6.90 & 6.90 & 7.24 & 7.20 \\
\hline
\end{tabular}

Table 5. Magnetic Moment and Reflectance Spectral data of Metal Chelates of PFSA ligand.

\begin{tabular}{|c|c|c|c|c|}
\hline Metal chelate & Magnetic Moment $\mu_{\text {eff }}$ (B. M.) & Molar Conductivity $\Omega \mathrm{m} \mathrm{ohm} \mathrm{cm}^{-1} \mathrm{~mol}^{-1}$ & Absorption band $\left(\mathrm{cm}^{-1}\right)$ & Transitions \\
\hline $\mathrm{Cu}-\mathrm{PFSA}$ & 1.55 & 9.79 & $\begin{array}{l}24610 \\
14954\end{array}$ & $\begin{array}{l}\text { C. T. } \\
{ }^{2} \mathrm{~B}_{1 \mathrm{~g}} \rightarrow{ }^{2} \mathrm{~A}_{1 \mathrm{~g}}\end{array}$ \\
\hline Ni-PFSA & 4.08 & 10.22 & $\begin{array}{l}22302 \\
15715\end{array}$ & $\begin{array}{l}{ }^{3} \mathrm{~A}_{2 \mathrm{~g}} \rightarrow{ }^{3} \mathrm{~T}_{1 \mathrm{~g}}(\mathrm{P}) \\
{ }^{3} \mathrm{~A}_{2 \mathrm{~g}} \rightarrow{ }^{3} \mathrm{~T}_{1 \mathrm{~g}}(\mathrm{~F})\end{array}$ \\
\hline Co-PFSA & 1.68 & 9.79 & $\begin{array}{l}24934 \\
19882 \\
2415\end{array}$ & $\begin{aligned} &{ }^{4} \mathrm{~T}_{1 \mathrm{~g}}(\mathrm{~F}) \rightarrow{ }^{6} \mathrm{~T}_{2 \mathrm{~g}}\left(\mathrm{v}_{1}\right) \\
&{ }^{4} \mathrm{~T}_{1 \mathrm{~g}}(\mathrm{~F}) \rightarrow{ }^{4} \mathrm{~A}_{2 \mathrm{~g}}\left(\mathrm{v}_{2}\right) \\
&{ }^{4} \mathrm{~T}_{1 \mathrm{~g}}(\mathrm{~F}) \rightarrow{ }^{4} \mathrm{~T}_{1 \mathrm{~g}}(\mathrm{P})\end{aligned}$ \\
\hline
\end{tabular}

$\mathrm{Zn}^{2+}$ Diamagnetic in Nature.

\subsection{Study of Antifungal activity}

The fungicidal activity of all the compounds was studied at $1000 \mathrm{ppm}$ concentration in vitro plant pathogenic organisms listed in Table 6. The antifungal activities of all the samples were measured by cup plate method [12]. Each of the plant pathogenic strains on potato dextrose agar (PDA) medium and that PDA medium contained potato 200 gms, dextrose $20 \mathrm{gms}$, agar $20 \mathrm{gms}$ and water 1 litre. 5 days old cultures were employed. The compounds to be tested were suspended (1000ppm) in PDA medium and autoclaved at $120^{\circ} \mathrm{C}$ for 15 min. at 15 atm pressure. These mediums were poured into sterile Petri plate and the organisms were inoculated after cooling the Petri plate. The percentage inhabitation for fungi 
was calculated after 5 days using the formula given below.

$$
\text { Percentage of inhibition }=\frac{100(X-Y)}{x}
$$

Where, X: Area of colony in control plate

Y: Area of colony in test plate

The fungicidal activity of all compounds is shown in Table 6.

Table 6. Antifungal Activity of Ligand PFSA $A_{1}$ and its metal chelates.

\begin{tabular}{llllll}
\hline \multirow{2}{*}{ Sample } & \multicolumn{6}{l}{ Diameter of Zone of Inhibition (In mm) } \\
\cline { 2 - 6 } & B. Subtilis & S. aureus & E. Coli & P. aeruginosa & C. albicans \\
\hline PFSA & 11 & 10 & 10 & 10 & 09 \\
Cu-PFSA & 11 & 12 & 16 & 15 & 07 \\
Ni-PFSA & 08 & 15 & 17 & 11 & 12 \\
Co-PFSA & 10 & 10 & 15 & 18 & 19 \\
Mn-PFSA & 08 & 16 & 16 & 13 & 11 \\
Zn-PFSA & 11 & 10 & 14 & 18 & 18 \\
Amoxicillin & 15 & 16 & 17 & 18 & 12 \\
\hline
\end{tabular}

Table 7. TGA of Matel chelates.

\begin{tabular}{lllll}
\hline \multirow{2}{*}{ Empirical Formula } & \multicolumn{4}{l}{$\%$ loss at temperature } \\
\cline { 2 - 5 } & $\mathbf{2 5 0}$ & $\mathbf{3 0 0}$ & $\mathbf{3 5 0}$ & $\mathbf{4 0 0}$ \\
\hline (PFSA)Cu ${ }^{2+}$ & 6.3 & 9.0 & 14 & 73 \\
(PFSA) $\mathrm{Ni}^{2+}$ & 7.0 & 23 & 61 & 76 \\
$\left(\right.$ PFSA) $\mathrm{Co}^{2+}$ & 7.08 & 12.11 & 21.31 & 69.24 \\
(PFSA) $\mathrm{Mn}^{2+}$ & 8.30 & 23.11 & 68.48 & 76.25 \\
(PFSA) $\mathrm{Zn}^{2+}$ & 7.05 & 12.10 & 21.30 & 69.21 \\
\hline
\end{tabular}

\section{Results and Discussion}

All the complexes are stable and non-hygroscopic. The metal complexes are insoluble in most organic solvents. The parent ligand PFSA was an amorphous brown powder, soluble in solvents like dioxane, DMSO and DMF. The results of elemental analysis of the ligand are reported in experimental part. They are consistent with the predicted structure as shown in Scheme-1.

\subsection{IR Spectra}

Examination of IR spectrum (not shown) of PFSA reveals that broad band of phenolic hydroxyl stretching is observed at $2900-3350 \mathrm{~cm}^{-1}$ as well as additional absorption bands at $3035,1540,1660$ are characteristics of the salicylic acid [13]. The strong bands at 1675 for $\mathrm{C}=\mathrm{O}$ and band at 3420 for sec. NH. The NMR data (shown in experimental part) also confirm the structure of PFSA.

The Metal chelate of PFSA with ions $\mathrm{Cu}^{2+}, \mathrm{Co}^{2+}, \mathrm{Ni}^{2+}$, $\mathrm{Mn}^{2+}$ and $\mathrm{Zn}^{2+}$ vary in colours. On the basis of the proposed structure as shown in Scheme-1, the molecular formula of the PFSA ligand is $\mathrm{C}_{25} \mathrm{H}_{20} \mathrm{~N}_{2} \mathrm{O}_{5}$. The complex coordinates with one central metal atom at four coordination sites and with two water molecules. Therefore the general molecular formula of the resulting metal chelate is $\left[\mathrm{C}_{25} \mathrm{H}_{20} \mathrm{~N}_{2} \mathrm{O}_{5}\right]_{2} \mathrm{M} .2 \mathrm{H}_{2} \mathrm{O}$ for divalent metal ions. This has been confirmed by results of elemental analysis reported in Table 4. The data are in agreement with the calculated values.

Inspection of the IR Spectra (not shown) of metal chelates reveals that all the spectra are identical in all respects. The comparison of IR spectrum of the parent ligand PFSA with that of its each metal chelates has revealed certain characteristics differences.

One of the significant differences to be expected between the IR spectrum of the parent ligand and its metal chelates is the presence of more broadened bands in the region of 3200$3600 \mathrm{~cm}^{-1}[14,15]$ for the metal chelates as the oxygen of the $\mathrm{O}-\mathrm{H}$ group of the ligands forms a coordination bond with the metal ions [16, 17]. This is explained by the fact that water molecule might have strongly absorbed to the metal chelates samples during their formation. Another noticeable difference is that the bands due to the $\mathrm{CO}$ at $1730 \mathrm{~cm}^{-1}$ in the IR spectrum of the each metal chelates. The band at $1400 \mathrm{~cm}^{-1}$ in the IR Spectrum of PFSA ligand assigned to inplane $\mathrm{OH}$ determination [14-17] is shifted towards higher frequency in the spectra of confirmed by a week bands at $1095 \mathrm{~cm}^{-1}$ corresponding to C-O-M starching [14-17]. Thus all of these characteristics features of the IR studies suggested the structure of the metal chelates as shown in figure 1.

\subsection{Electronic Absorption Spectra and Magnetic Moment}

Examination of data of the metal content in each compound revealed a 1:2 metal: ligand (M: L) stoichiometry in all of the chelate of divalent metal ions. Magnetic moment $\left(\mu_{\text {eff }}\right)$ of each of the metal chelates is given in Table 2. Examination of these data reveals that all chelates other than that of $\mathrm{Zn}^{2+}$, are Para magnetic while those of $\mathrm{Zn}^{2+}$ are diamagnetic.

\subsection{Copper and Nickel Complexes}

The diffuse electronic spectrum of the [CuPFSA $\left.\left(\mathrm{H}_{2} \mathrm{O}\right)_{2}\right]$ metal complex shows broad bands at 14954 and $24610 \mathrm{~cm}^{-1}$ due to the ${ }^{2} \mathrm{~B}_{1 \mathrm{~g}} \rightarrow{ }^{2} \mathrm{~A}_{1 \mathrm{~g}}$ transition [18] and charge transfer, respectively suggesting a distorted octahedral structure [1921] for the [CuPFSA $\left(\mathrm{H}_{2} \mathrm{O}\right)_{2}$ ] complex. Which is further confirmed by the higher value of $\mu_{\text {eff }}$ of the [CuPFSA $\left.\left(\mathrm{H}_{2} \mathrm{O}\right)_{2}\right]$ complex. The [NiPFSA $\left(\mathrm{H}_{2} \mathrm{O}\right)_{2}$ ] and [CuPFSA $\left(\mathrm{H}_{2} \mathrm{O}\right)_{2}$ ] complex gave two absorption bands respectively at 15715 , 22302 and $14954,24610 \mathrm{~cm}^{-1}$ corresponding to ${ }^{3} \mathrm{~A}_{2 \mathrm{~g}} \rightarrow{ }^{3} \mathrm{~T}_{1 \mathrm{~g}}(\mathrm{P})$ and ${ }^{3} \mathrm{~T}_{1 \mathrm{~g}}(\mathrm{~F})$ transitions. Thus absorption bands at the diffuse, reflectance spectra and the value of the magnetic moments $\mu_{\text {eff }}$ indicate and octahedral configuration for the [NiPFSA $\left.\left(\mathrm{H}_{2} \mathrm{O}\right)_{2}\right]$ and [CuPFSA $\left(\mathrm{H}_{2} \mathrm{O}\right)_{2}$ ] complex [22].

\subsection{Manganese and Zink Complexes}

The spectra of [MnPFSA $\left(\mathrm{H}_{2} \mathrm{O}\right)_{2}$ ] shows weak bands at 16717, 18406 and $23751 \mathrm{~cm}^{-1}$ assigned to the transitions ${ }^{6} \mathrm{~A}_{1 \mathrm{~g}} \rightarrow{ }^{6} \mathrm{~A}_{1 \mathrm{~g}} \quad\left({ }^{4} \mathrm{E}_{\mathrm{g}}\right), \quad{ }^{6} \mathrm{~A}_{1 \mathrm{~g}} \rightarrow{ }^{4} \mathrm{~T}_{2 \mathrm{~g}} \quad\left({ }^{4} \mathrm{G}\right), \quad{ }^{6} \mathrm{~A}_{1 \mathrm{~g}} \rightarrow{ }^{4} \mathrm{~T}_{1 \mathrm{~g}} \quad\left({ }^{4} \mathrm{G}\right)$, respectively suggesting an octahedral structure for the [MnPFSA $\left(\mathrm{H}_{2} \mathrm{O}\right)_{2}$ ] chelate. The high intensities of the bands suggests that they might be charge transfer in origin $\mu_{\text {eff }}$ is found to be lower than normal range. In the absence of low temperature moments it is difficult to give any significance. As the spectrum of the $\left[\mathrm{ZnPFSA}\left(\mathrm{H}_{2} \mathrm{O}\right)_{2}\right]$ polymer is not well resolved, it is not interpreted but it is $\mu_{\text {eff }}$ value shows that it is diamagnetic as expected. 


\subsection{Molar Conductance Measurements}

Conductivities of all the complexes were measured in acetonitrile solvent and all the complexes were found to be electrolytic [15] in nature of 1:2 type and molar conductivity values are in the range of 32.3-36.7 $\mathrm{Ohm}^{-1} \mathrm{Cm}^{-1}$.

\subsection{Antifungal Activity}

The antifungal activity of all the compounds measured for various plant pathogens. Inspection of the result shown in Table 3 indicates that all compounds are good toxic for fungi. Out of all the compounds copper chelates is more toxic than other. These compounds almost inhibit the fungi about $72 \%$. Hence produced metal chelates can be employed as garden fungicides. Further work in the direction is in progress.

\section{Conclusion}

Metal complexes of PFSA ligands derived from Ethyl 5(piperidine-1-ylmethyl)Furan-2-carboxylate and 4-amino salicylic acid were prepared and characterized by elemental analysis, FTIR and UV-Vis. Spectra, conductivity measurements and magnetic susceptibilities. The $\mathrm{Ni}$ (II) $\mathrm{Cu}$ (II), Co (II) and Mn (II) complexes possess show octahedral geometry around the central metal ion.

\section{Acknowledgements}

I am really grateful to my guide, Dr. Asha D. Patel for their necessary suggestion, providing valuable insights into seeing the whole paper. I would like to thank and feel gratitude to her from the core of my heart.

\section{References}

[1] Vagdevi HM, Vaidya VP. Ind J Heterocyclic Chem. 2001; 10, 253-260.

[2] DesaiNC, SatodiyaHM, Rajpara KM, Joshi VV, Vaghani HV, J. Saudi Chem. Soc.; 2014; doi: 10.1016; j. jscs. 2013; 12.005.

[3] PadmashaliB, VaidyaVP, VijayaKumarMLA, Ind. J. HeterocyclicChem. 2002; 12 (2), 89-94.

[4] Mahadevan KM, Vaidya VP, Vagdevi HM, Ind. J. Chem. 2003; 42B (8), 1931-1936.

[5] VarshneyMM, Husain A, Parcha V, Med. Chem. Res. 2014; 23 (9), 4034-4041.
[6] Ravindra KV, Vagdevi HM, Vaidya VP, Ind. J. Chem. 2008; 47B (8), 1271-1276.

[7] Mohanambal D, Antony S. A., 2014, Int. J. Pharma. Bio. Sci., $5(3), 600-611$.

[8] El-BindaryA. A., GhoneimMM, DiabMA, El-SonbatiA. Z., SeragLS, J. hermodyn. Catal., 2014; 5 (2), 135.

[9] Ukrainczyk M, GredicakM, Jeric I, Kralj D, Cryst. Growth Des. 2014; 14 (9), 4335-4346.

[10] Tilborg A, NorbergB, Wouters J, Eur. J. Chem. 2014; 74, 411426.

[11] Hong S, Nebbioso A, CarafaV, ChenY, Yang B, Altucci L, You Q, Bioorg. Med. Chem., 2008; 17 (1), 7992-8002.

[12] Baily WR, Scott EG, Diagnostic Microbiology, The C. V. Moshy Co. St. Lovis, 1966; 257.

[13] Bhatt AK, Shah PK, Karadia HG, Patel HD, Orient. J. Chem., 2003; 19 (3), 704-706.

[14] Silverstein RM, Spectrometric Identification of organic compounds, $5^{\text {th }}$ Ed., John Wiley, 1991.

[15] Kemp W, Organic Spectroscopy ELBS. Macmillan, UK, 1998.

[16] Nakamoto K, Infared Spectra of Inorganic and Co-Ordination Compound, Wiley, NY, 1970.

[17] Lever A. P, Inorganic Electronic Spectroscopy, Elsevier, NY, 1968.

[18] Figgis BN, Introduction to Ligands Field, Wiley Eastern Ltd. NY, 1976.

[19] Carlin RN, Dryneveldt AJV, Magnetic properties of Transition Metal Compound, Springe-Berlag, NY, 1997.

[20] Patel JC, Dholariya HR, PatelKS, Patel KD, Appl. Organomet. Chem., 2012; 26 (11), 604-613.

[21] Kettle FA, 1975, Coordination Compounds, Thomas Nelson \& Sons.

[22] Patel J. C., Dholariya H. R., Patel K. S., Bhatt J., Patel K. D., 2014, Med. Chem. Res., 23 (8), 3714-3724.

[23] Patel Harshadkumar P., Patel Sefali S. and Patel Asha D. Journal 2015, of Chemical and Pharmaceutical Research, 7 (9): 690-694.

[24] Patel Harshadkumar P., 2018, International Journal of Current Advanced Research; Volume 7; Issue 2 (I); 10216-10219.

[25] Patel Harshadkumar P. and Patel Asha D., 2016, Der Pharma Chemica, 2016, 8 (1): 462-466. 